\title{
PHENOMENOLOGICAL ANALYSIS OF A CONCEPTUAL WATERJET PROPULSOR BASED ON THE COANDA EFFECT
}

\author{
R. L. Lemos ${ }^{a}$, \\ C. H. Marques ${ }^{a}$, \\ L. A. $\operatorname{Rocha}^{\mathrm{b}}$, \\ ABSTRACT \\ This work is part of a research project conceived at the Federal University \\ of Rio Grande. The project aims to create and develop mechanical devices \\ that use the Coanda effect to enhance their overall efficiency. The focus \\ herein is analyzing the physical phenomenon occurring in a conceptual \\ water-jet propulsor. In the proposed concept, a water-jet propulsor has its \\ impeller replaced by injectors that produce the so-called Coanda effect, \\ increasing thereby the mass flow rate. In order to simulate the flow through \\ the propulsor, a numerical model was developed. In this model the time- \\ averaged conservation equations of mass and momentum were solved \\ numerically by the finite volume method, more precisely with the \\ commercial package ANSYS FLUENT (version 14.0). For the closure of \\ the constitutive equations, the k- $\omega$ URANS turbulence model was \\ employed. The simulation was performed for a transient state with a \\ timestep of $\Delta t=1 \times 10^{-3} \mathrm{~s}$ and a total physical time of $t=6.0 \mathrm{~s}$. Static \\ pressure fields, streamlines and speed profiles are used to analyze the \\ equipment performance and the phenomenon occurrence. The results show \\ that the Coanda Effect is able to generate thrust in a waterjet propulsion \\ device without impeller. The study suggests that the employment of this \\ principle has promising applicability in marine propulsion and deserves \\ attention on future works.

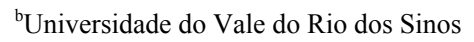 \\ Escola Politécnica \\ Av. Dr. Nilo Peçanha, 1600 \\ CEP 91330-002, São Leopoldo, RS, Brasil \\ luizor@unisinos.br \\ Received: February 18, 2019 \\ Revised: February 28, 2019 \\ Accepted: March 26, 2019 \\ Keywords: propellers; CFD analysis; Coanda effect; waterjet propulsion
}

\section{NOMENCLATURE}

$\mathrm{A}_{\mathrm{b}} \quad$ nozzle narrowing angle, ${ }^{\circ}$

$\mathrm{C}_{\mathrm{T}} \quad$ non-dimensional thrust loading coefficient

cte constant

D diameter of a hypothetical actuator disk, $m$

g gravity acceleration, $\mathrm{m} / \mathrm{s}^{2}$

$\Delta \mathrm{h} \quad$ fluid column difference height, $\mathrm{m}$

$\mathrm{K}$ turbulent kinetic energy, $\mathrm{kg} \cdot \mathrm{m}^{2} / \mathrm{s}^{2}$

$\mathrm{L}$ chord length, $\mathrm{m}$

$\mathrm{P} \quad$ static pressure, $\mathrm{Pa}$

$\mathrm{P}_{\mathrm{k}} \quad$ limiting function

$R_{c} \quad$ curvature radius of the Coanda surface, $m$

$\mathrm{R}_{\mathrm{e}} \quad$ Reynolds number

$\mathrm{t}$ time, $\mathrm{s}$

$\mathrm{T}$ thrust force, $\mathrm{N}$

$\mathrm{v}_{\mathrm{a}}$ advance velocity of a vessel, $\mathrm{m} / \mathrm{s}$

$\mathrm{u} \quad$ velocity unity at the $\mathrm{x}$-axis, $\mathrm{m} / \mathrm{s}$

v velocity unity at the $y$-axis, $\mathrm{m} / \mathrm{s}$

$V$ flow velocity relative at control volume, $\mathrm{m} / \mathrm{s}$

$\mathrm{x}, \mathrm{y}, \mathrm{z}$ cartesian coordinates

\section{Greek symbols}

$\alpha_{1}, \beta, \beta_{1}, \beta_{2}, \sigma_{k}, \sigma_{\omega}, \sigma_{\omega 2}$ SST $k$ - $\omega$ model parameters

$\omega$ turbulent kinetic energy dissipation rate, $\mathrm{kg} \cdot \mathrm{m}^{2} / \mathrm{s}^{2}$

$\tau_{i j} \quad$ shear stress tensor, $\mathrm{N} / \mathrm{m}^{2}$

$\tau_{w} \quad$ shear stress tension in an infinitesimal element, $\mathrm{N}$

$\eta_{i} \quad$ ideal axial efficiency of an actuator disk

$\eta_{\mathrm{o}} \quad$ efficiency of an ideal waterjet system

$\rho \quad$ fluid density, $\mathrm{kg} / \mathrm{m}^{3}$

$\mu \quad$ dynamic viscosity, $\mathrm{kg} / \mathrm{m}$.s

$\mu_{t} \quad$ turbulent dynamic viscosity, $\mathrm{kg} / \mathrm{m} . \mathrm{s}$

$v \quad$ kinematic viscosity, $\mathrm{m}^{2} / \mathrm{s}$

$v_{\mathrm{t}} \quad$ turbulent kinematic viscosity, $\mathrm{m}^{2} / \mathrm{s}$

\section{INTRODUCTION}

Modern marine propulsion systems rely on several types of mechanisms that transform mechanical energy into kinetic energy to move a 
vessel. It can be found propulsive systems based on propellers, sails, waterjets and so on. Each of these systems has specific characteristics inherent to the mechanics of its components. Consequently, each system also has specific applicability, depending on the task that the vessel has been assigned to perform.

In general, waterjet propulsion systems are used in situations where high speeds are desired for a marine vehicle. These systems can provide great maneuverability and have lower mechanical losses than the conventional propellers (Eslamdoost, 2014). Waterjet systems hold high conversion rates of mechanical energy into thrust for marine vehicles. However, the energy consumption can still be considerably high due to mechanical transmission losses or the cavitation of the impeller blades.

In the present work, a waterjet propulsor based on the Coanda effect is proposed. To accomplish that, a numerical analysis was performed in order to increase the understanding of the physics behind of the flow behavior inside the device.

The employment of this device on marine propulsion, brings some phenomenological differences in comparison with the conventional jet propulsion devices. Thus, the main objective of this study is to improve the knowledge about the phenomenology of the flow in device for the future development of propulsive systems based on Coanda effect. Besides contributing to the theoretical foundation around the Coanda Effect it is by itself a scientific achievement for the fluid mechanics and numerical modeling fields.

\section{RELEVANT TOPICS ABOUT PROPULSION SYSTEMS}

In general, conventional propellers are successful elements as thrust providers in most of ships applications nowadays. However, for some smaller-scale applications, alternative propulsion systems are chosen, because the overall efficiency of the screw propeller decreases as its diameter decreases. Following the equation presented in Woud and Stapersma (2013), the ideal axial efficiency of an actuator disk is given by:

$$
\eta_{i} \stackrel{\operatorname{def}}{=} \frac{2}{\left(1+\sqrt{\left(1+C_{T}\right)}\right)}
$$

where $C_{T}$ is the non-dimensional thrust loading coefficient of the actuator disk. This coefficient, in its turn, is defined by:

$$
C_{T}=\frac{T}{\left(0.5 \times \rho \times v_{\alpha}^{2} \times 0.25 \times \pi \times D^{2}\right)}
$$

where $T$ is the thrust generated by the disk, $\rho$ is the density of the water, $v_{a}$ is the advance velocity and $D$ is the diameter of the actuator. From Eq. (1) and (2), it is possible to notice that the efficiency of the actuator disk is inversely proportional to the load coefficient, and this is inversely proportional to the disk diameter. Thus, the use of propeller in smaller propulsive systems becomes significantly less efficient

Comparatively waterjet propulsion systems, used ordinarily in small marine vehicles such as jetskis and speedboats, are widely used in vehicles that demand higher speed (Borrett, Rae, 2008). One of the advantages of this type of system is the high energy conversion efficiency of the impeller. The thrust power generated by the impeller is function of the velocities, inlet and outlet areas. These areas are designed according to the aspiration and ejection effect they must cause in the openings of the hull, as indicated in the literature (Carlton, 2012). Figure 1 illustrates the typical arrangement of a waterjet propulsor.

Although the working principle of a waterjet propulsor is very much the same as a conventional propeller, its integration to the hull is different, making it hard to use the same concepts for studying both propulsion types. The net thrust of the propeller can be obtained by measuring the force transmitted through its shaft. On the other hand, as there is not just a single contact point between the waterjet unit and the hull, this cannot be easily accomplished in waterjet propulsion. Instead, another force of simpler measurement is defined to express the magnitude of

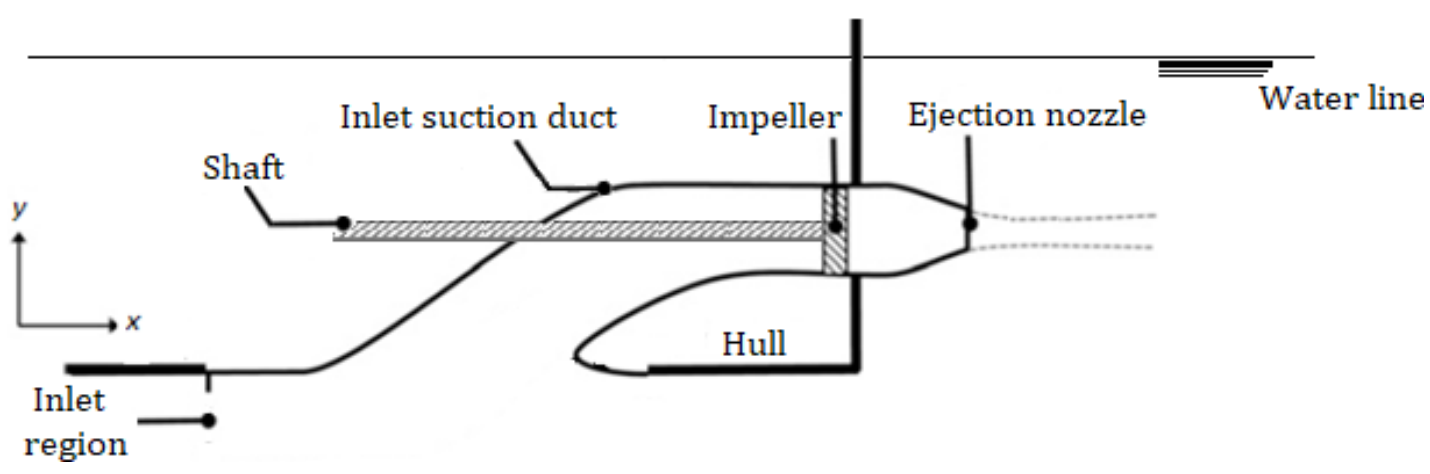

Figure 1. Waterjet propulsor arrangement. (Adapted from Eslamdoost et al., 2016) 
the thrust. The new thrust is called gross thrust and is obtained by the measurement of the momentum flux change through the waterjet control volume.

The efficiency of a waterjet propulsion unit is defined by:

$$
\eta_{0}=\left[\frac{v_{2}\left(v_{2}-v_{1}\right)}{0.5\left(v_{2}^{2}-v_{1}^{2}\right)+g \cdot \Delta h}\right]
$$

where $v_{s}, v_{2}$ and $v_{1}$ are respectively the vessel velocity, the outlet velocity and inlet velocity in the control volume, and $\Delta h$ is the height difference between the inlet and outlet nozzles. As can be seen in Eq. (3), the efficiency of a water jet propulsion system can be related to the inlet and outlet velocities of the propulsive unit. This characteristic implies that the efficiency of these systems resides fundamentally in the geometry of the device, since the speed gain is given by the area difference between the intake and ejection nozzles.

\section{MARINE PROPULSOR BY COANDA EFFECT (PMEC)}

Flow amplification devices using Coanda effect have become popular thanks to advances in the field of computational fluid dynamics. In several studies presented in the literature, there are ingenious proposals in which the physical phenomenon is used to improve the efficiency of flow machines (Djojodihardjo et al., 2011), aerodynamic profiles (Trancossi et al., 2016b; Lim et al., 2011), and also the positioning systems for underwater vehicles (Mazumdar et al., 2015).

The propulsive unit model presented in this work is a subsequent part of the research developed by Lemos (2016) and Lemos et al. (2017). The project aims to study the application of mass flow amplification generated by the Coanda effect to enhance overall efficiency in fluid systems. The present study proposes to use the Coanda effect in a waterjet propulsion unit in which the impeller components are replaced by water injectors. The small openings inserted into the inner surfaces of the device inject fluid at high speed tangentially on hydrodynamic surfaces. This generates an intense pressure gradient that creates propulsive force on the device. This gradient is generated only due to the phenomenon known as Coanda effect (Trancossi et al., 2016a).

The device proposal is herein called Marine Propulsor by Coanda Effect (PMCE, which is the acronym initials that comes from the Portuguese name: Propulsor Marítimo por Efeito Coanda). The device is geometrically similar to conventional waterjet units and holds similar dimensional construction parameters. Figure 2 shows the geometry adopted for the PMEC model addressed in this work. Note that in Fig. 2, the dimensions are reduced, so that the scale of the figure could provide a good visualization of the region of interest for the study. The illustration shows a two-dimensional cross-sectional area of the device integrated to the hull of a hypothetical vessel, similarly to the model shown in Fig. 1. The geometry shown is divided into 3 regions of analysis. Four control lines are also placed along the intake duct to facilitate the presentation of the results.

The PMEC unit differs from the traditional waterjet as regards the way it turns the mechanical energy of the pump into thrust force for the vessel. The Coanda effect, which basically translates to the adherence phenomenon of a fluid to a solid interface, creates lift forces in the internal region of the device similarly to what occurs on aeronautical profiles. The highlight of this propulsion model is that the lift forces generated by the pressure fields are purposely oriented to increase the thrust force.

\section{MATHEMATICAL MODEL}

The mathematical modeling in accordance with the simplifying hypotheses considered in the physical

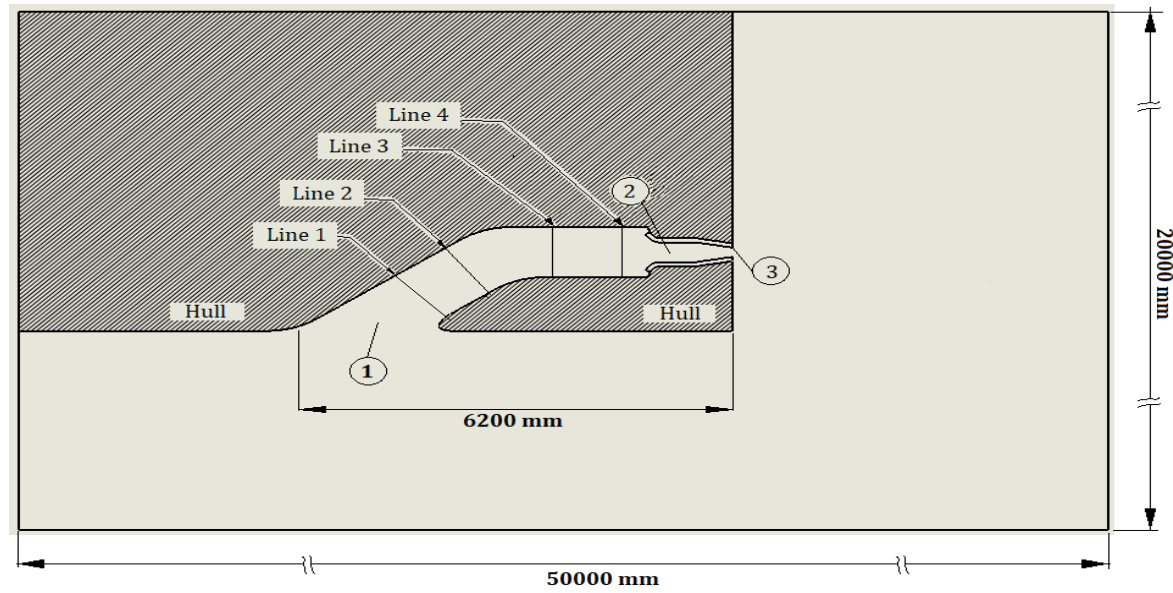

Figure 2. Computational domain of the PMCE-proposed. 
model was based on an incompressible, turbulent, transient, two-dimensional domain and constant thermophysical properties. In order to solve the problem, the time-averaged conservation equations of mass and momentum (RANS - Reynolds Averaged Navier-Stokes) are used, together with the SST $k-\omega$ turbulence model, to closure the equations system.

The time-averaged conservation equations are listed in the works published by Wilcox (2008). The conservation equation of mass is given by:

$$
\frac{\partial \bar{u}}{\partial x}+\frac{\partial \bar{v}}{\partial y}=0
$$

The time-averaged conservation equation of momentum in $x$ and $y$ directions are given respectively by:

$$
\begin{aligned}
& \frac{\partial(\rho \bar{u})}{\partial t}+\frac{\partial(\rho \bar{u})}{\partial x}+\frac{\partial(\rho \overline{u v})}{\partial y}=-\frac{\partial \bar{p}}{\partial x}+\left(\mu+\mu_{t}\right)\left(\frac{\partial^{2} \bar{u}}{\partial x^{2}}+\frac{\partial^{2} \bar{u}}{\partial y^{2}}\right) \\
& \frac{\partial(\rho \bar{v})}{\partial t}+\frac{\partial(\rho \overline{v u})}{\partial x}+\frac{\partial(\rho \bar{v})}{\partial y}=-\frac{\partial \bar{p}}{\partial x}+\left(\mu+\mu_{t}\right)\left(\frac{\partial^{2} \bar{v}}{\partial x^{2}}+\frac{\partial^{2} \bar{v}}{\partial y^{2}}\right)
\end{aligned}
$$

where: $\rho$ is the density of the fluid $\left[\mathrm{kg} / \mathrm{m}^{3}\right], x$ represents the cartesian spatial coordinate in the direction of the $x$-axis $[\mathrm{m}], u$ is the velocity component in the direction of the $x$-axis $[\mathrm{m} / \mathrm{s}], y$ represents the spatial Cartesian coordinate in the $y$ axis direction, $[\mathrm{m}], v$ is the velocity component in the $y$-direction $[\mathrm{m} / \mathrm{s}]$, and $P$ is pressure $\left[\mathrm{N} / \mathrm{m}^{2}\right]$. The turbulent viscosity is given by:

$$
\mu_{t}=\frac{\bar{\rho} \alpha_{1} k}{\max \left(\alpha_{1} \omega S F_{2}\right)}
$$

To obtain the turbulent viscosity $(\mu t)$, the $k$ - $\omega$ model solves two transport differential equations for the kinetic energy of the turbulence $(k)$ and the specific dissipation rate $(\omega)$, which are given respectively by:

$$
\frac{\partial k}{\partial t}+\frac{\partial\left(\bar{u}_{j} k\right)}{\partial x_{i}}=\bar{P}_{k}-\frac{k^{3 / 2}}{L_{T}}+\frac{\partial}{\partial x_{i}}\left[\left(\mu+\sigma_{k} \mu_{t}\right) \frac{\partial k}{\partial x_{j}}\right]
$$

$$
\begin{aligned}
& \frac{\partial \omega}{\partial t}+\frac{\partial\left(\bar{u}_{j} \omega\right)}{\partial x_{i}}=\left(\frac{\alpha}{\mu_{T}}\right) \bar{P}_{k}-\beta \omega^{2}+\frac{\partial}{\partial x_{i}}\left[\left(\mu+\sigma_{\omega} \mu_{t}\right) \frac{\partial \omega}{\partial x_{j}}\right] \\
& +2\left(-F_{1}\right) \frac{\sigma_{\omega 2}}{\omega} \frac{\partial k}{\partial x_{i}} \frac{\partial \omega}{\partial x_{i}}
\end{aligned}
$$

where: $k$ is the turbulent kinetic energy, $P_{k}$ is a limiting function that prevents the generation of turbulence in stagnant regions, and $\omega$ is the specific dissipation rate. For the closure of the equations, Menter (1994) proposes the use of semi-empirical coefficients in the calculations of specific dissipation rates and turbulent kinetic energy.

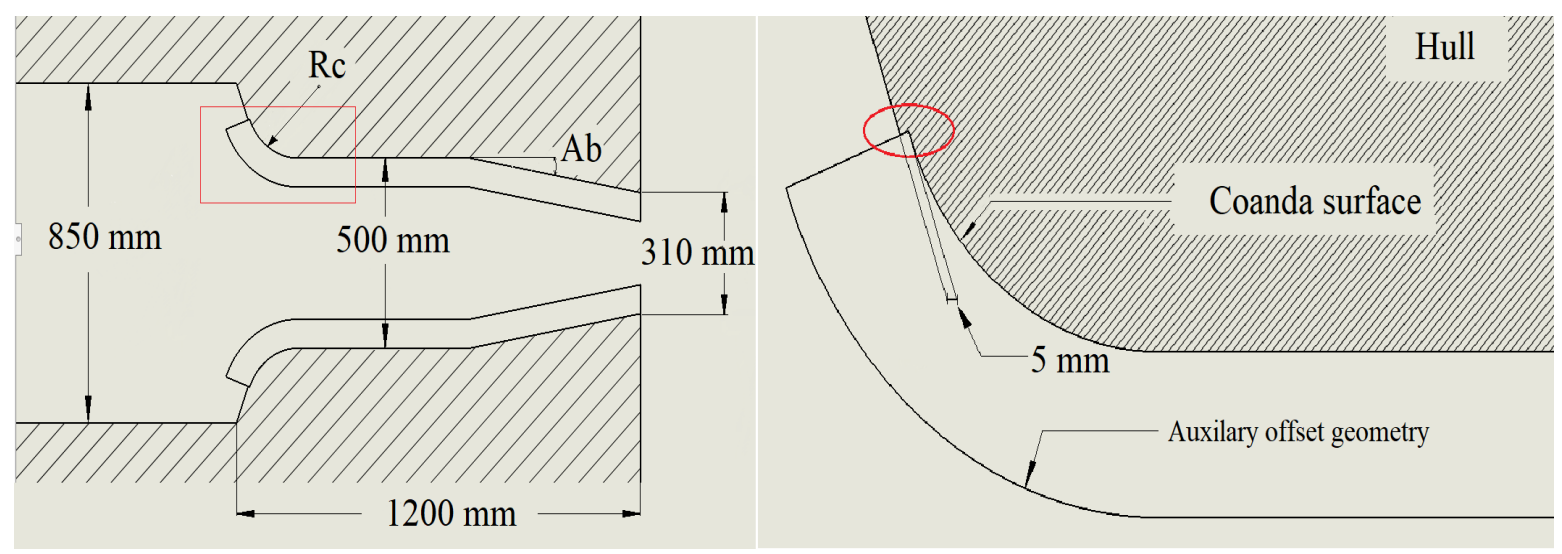

Figure 3. Geometry proposed and detail of the Coanda surface inside the propulsor model.

The suggest values for the coefficients, which were obtained by test approximations in physical models, are listed in Tab. 1.

Table 1. Coefficients values from the SST model.

\begin{tabular}{ccccccccc}
$\beta$ & $\alpha_{1}$ & $\beta_{1}$ & $\sigma_{k}$ & $\sigma_{\omega}$ & $\sigma_{2}$ & $\beta_{2}$ & $\sigma_{2}$ & $\sigma_{\omega 2}$ \\
\hline 0.09 & $5 / 9$ & $3 / 40$ & 0.85 & 0.5 & 0.44 & 0.08 & 1 & 0.856
\end{tabular}

\section{PROBLEM DESCRIPTION}

In the investigation of the flow through the PMEC unit proposed in this work, a numerical approach is taken to obtain the fields of pressures and speeds along the device. Therefore, the Finite Volume Method implemented in ANSYS FLUENT (version 14.0) software is used to perform the present simulations.

For the numerical approach, a two-dimensional 
computational domain was designed to recreate the geometry of a PMEC unit. The geometry of the ejection nozzle can be seen in detail in Fig. 3. The curvature radius of the Coanda surface adjacent to the water injectors $(R c)$, is $150 \mathrm{~mm}$, while the nozzle narrowing angle, $(A b)$ is $10^{\circ}$. The overall length of the analysis region 2 is approximately $1200 \mathrm{~mm}$

The two injectors installed just before the Coanda surface are the only sources of energy inputted into the domain. The injector nozzles have 5 $\mathrm{mm}$ each and impel water at an initial velocity of 70 $\mathrm{m} / \mathrm{s}$ tangentially on the curved surfaces.

Figure 3 also illustrates how it is the arrangement of these elements in the domain. The domain discretization process produced a mesh of 200,000 volumes, which received refinement treatment in the regions close to curved surfaces and injection nozzles. The boundary condition imposed on all edges of the domain was of pressure output, except on the injectors, where the boundary condition is of prescribed velocity.

The ANSYS 14.0 package performs the spatial and numerical discretization of conservation equations using the finite volume method (ANSYS, 2007). The SIMPLEC coupling algorithm and second order upwind discretized interpolation functions are employed. The viscosity model adopted is the SST $k$ $\omega$. The numerical models are decided according to recommendations for problems involving Coanda flows and high complexity surfaces, presented by Seo et al. (2017), Trancossi et al. (2016a), Mazudar et al. (2015) and Versteeg and Malalasekera (2007). Given that the study case is a turbulent flow with intense pressure gradients, a time-dependent model with a timestep of $1.0 \times 10^{-3} \mathrm{~s}$ and total time of $6.0 \mathrm{~s}$ is adopted.

The workstation used for the simulation runs hold the following configuration: processor Intel Core i7-4960X, operational system Windows Vista 64-bit, CPU with 12 cores of $3.60 \mathrm{GHz}$, GPU with 32 GB of RAM and a graphic card GTX-720. The total simulation time was around 80 hours.

\section{RESULTS AND DISCUSSION}

At the end of the simulations, the flow behavior inside the propulsion unit was analyzed, and phenomenology evaluation could be performed. The simulation achieved consistent results, with good convergence rate and results physically compatible with similar studies about waterjet devices.

Figure 4 shows the streamlines and the magnitude of the velocity fields through the propulsion device PMEC. The streamlines reveal that the injectors are able to reproduce the Coanda effect in the internal region of the device. This finding is confirmed by observing that a considerable amount of water is suctioned by the inlet located in the analysis region 1 .

This event indicates that the pressure gradient on the Coanda surfaces is high enough to induce the surrounding water to pass through the propulsion system, similar to what an impeller does in a conventional water-jet unit.

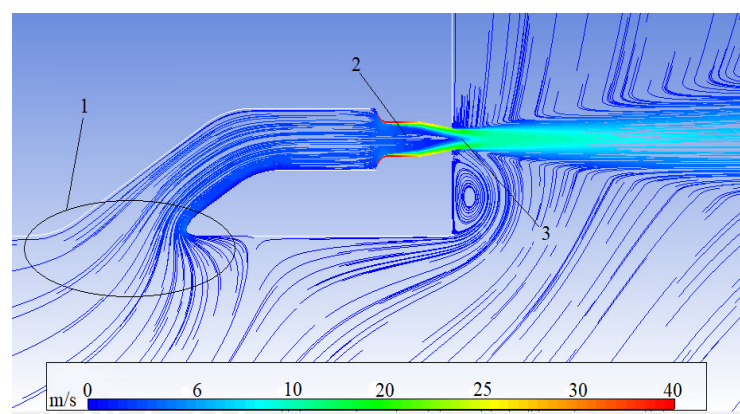

Figure 4. Streamlines and velocity magnitude contours of the flow through the PMEC.

Figure 5 shows in detail the behavior of the flow in region 2 of the device. The streamlines reveal that the jets from the injectors, move large amount of water, a phenomenon associated with the Coanda effect. Water is injected at $70 \mathrm{~m} / \mathrm{s}$ and rapidly lose energy due to the viscous forces, such a way that the average speed at the injector nozzle outlet is significantly lower than that injected.

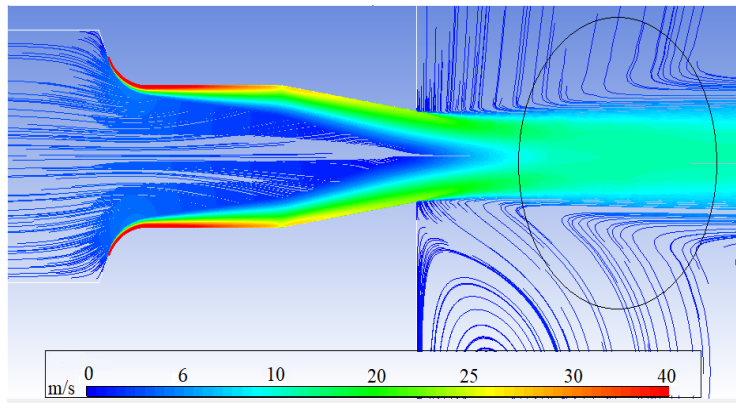

Figure 5. Streamlines and velocity magnitude contours in region 2.

The energy loss of the flow is represented by the change of coloration in the streamlines, ranging from red (high speed) to blue (low speed). Figures 5 and 6 indicate further that part of the water mass located in region 3 is induced to move due to the viscous effects of the jet ejected by the outlet nozzle, forming a recirculation zone.

Figure 6 shows the field of static pressures in region 2 . This figure shows that the flow direction change caused by the Coanda effect generates a lowpressure zone (blue color), responsible for suctioning water at the device inlet. The region near the Coanda surfaces are the one to present the lowest values of pressure. The pressure field reaches average values of $-8.5 \mathrm{kPa}$ between the two surfaces. In the ejection region, the red coloration indicates positive pressures values, that reach up to $10 \mathrm{kPa}$.

In order for the color scale to distinguish the 
regions of interest more clearly in Fig. 6, the range between $-20 \mathrm{kPa}$ and $+20 \mathrm{kPa}$ was set up. Hence, the discolorations observed in some points are pressure values outside this range.

Figure 7 shows velocity profiles in different positions as the flow displaces towards to the outlet of the PMEC unit. The profiles show that the water mass suctioned speed up as approaches the Coanda surfaces by integrating the speed profiles, a mass flow rate of $2488 \mathrm{~kg} / \mathrm{s} . \mathrm{m}$ in the control line 1 and timestep $6 \mathrm{~s}$ was found. This value is significant when compared to the total mass flow rate of 3306 $\mathrm{kg} / \mathrm{s} . \mathrm{m}$ that is ejected by the PMEC unit. Remarkably, over $75 \%$ of the mass flow ejected is due to the Coanda effect.

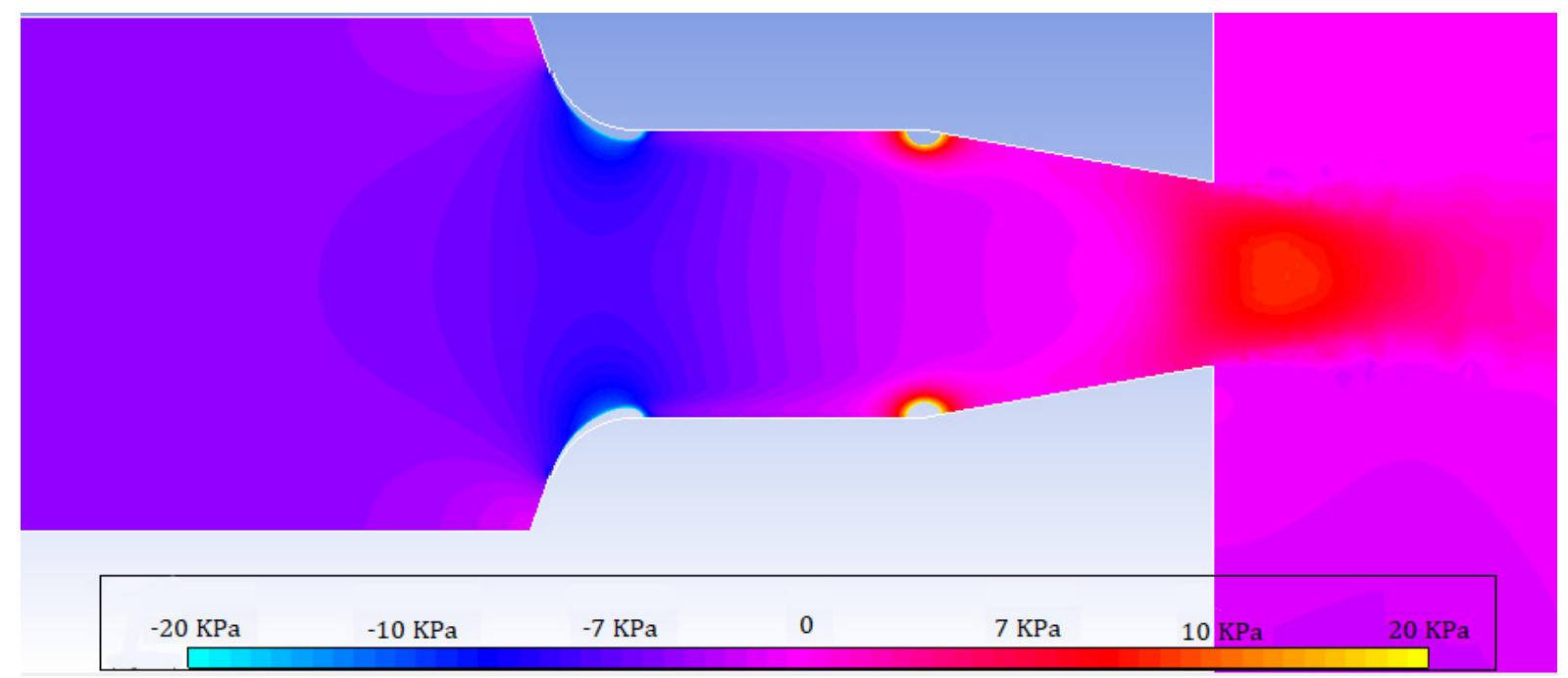

Figure 6. Static pressure contours on the interior of the PMEC.

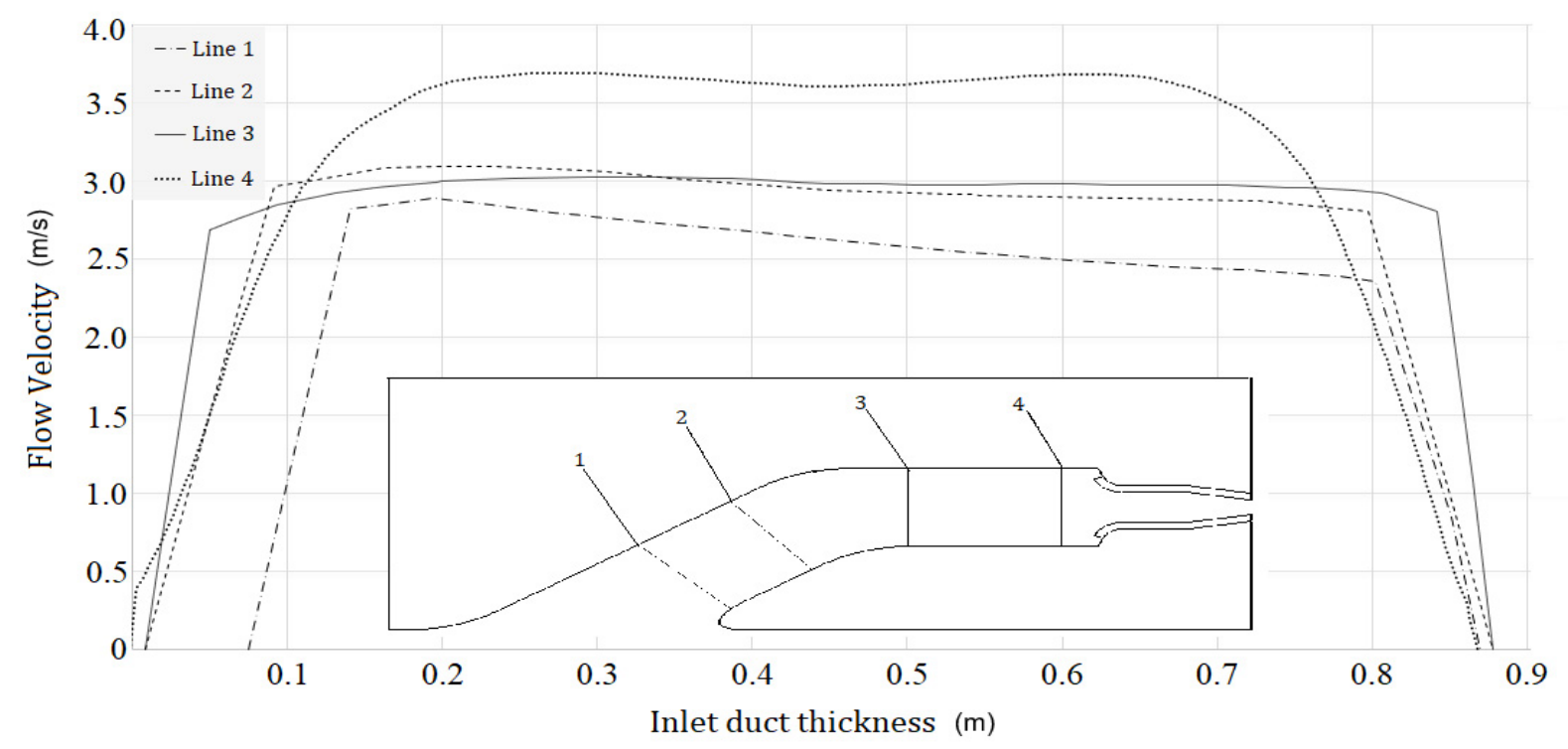

Figure 7. Flow velocities profiles at each control line through the propulsion device.

\section{CONCLUSIONS}

This study proposed a conceptual marine propulsor, similar to conventional waterjets, but that uses Coanda effect in replacement to the impeller. The results revealed that most part of the mass flow rate ejected by the PMEC unit goes through it due to the inner pressure fields produced by the Coanda effect.

This spontaneous physical phenomenon proved to be capable of providing an ejection mass flow of 4 times higher the mass flow injected by the nozzles without extra energy consumption. Moreover, one possible advantage of the proposed concept would be the reduction of cavitation risk since this problem is inherent in conventional waterjet units due to the presence impeller.

Summing up, the Coanda effect application in propulsion devices was demonstrated to be an actual possibility that deserves further investigation on phenomenology and feasibility. 


\section{ACKNOWLEDGEMENTS}

The author R. L. Lemos thanks CNPq for the scholarship. The authors E. D. dos Santos, L. A. Isoldi and $\mathrm{L}$. A. Rocha are grateful to $\mathrm{CNPq}$ for the research productivity grants (Processes: 306024 / 2017-9, 306012 / 2017-0, 307847 / 2015-2).

\section{REFERENCES}

ANSYS Inc., 2007, ANSYS Fluent Theory Guide, 15th Edition, United States.

Borrett, D., and Rae, P., 2008, Waterjet Applications in Vessels that Operate in Multiple Modes, Royal Institution of Naval Architects Waterjet Propulsion 5.

Carlton, J. S., 2012, Marines Propeller and Propulsion, 3rd Edition, Waltham, ButterworthHeinemann.

Djojodihardjo, H., AbdulHamid, M. F., Basri, S., Romli, F. I., and Madij, D. L. A., 2011, Numerical Simulation and Analysis of Coanda Effect Circulation Control for Wind-Turbine Application Considerations, IIUM Engineering Journal, Vol. 12, pp. 19-42.

Eslamdoost, A., Larsson, L., Bensow, R., 2014, Waterjet Propulsion and Thrust Deduction, Journal of Ship Research, Vol. 58, No. 4, pp. 2012-2015.

Lemos, R. L., 2016, Análise Numérica com Escoamento Turbulento sobre Perfis Hidrodinâmicos, Trabalho de Conclusão de Curso em Engenharia Mecânica Naval, Escola de Engenharia, Universidade Federal do Rio Grande (FURG), Rio Grande, RS. (in Portuguese)

Lemos, R. L., Vieira, R. S., Isoldi, L. A., Rocha, L. A. O., Pereira, M. dos S., and dos Santos, E. D., 2017, Numerical Analysis of a Turbulent Flow with Coanda Effect in Hydrodynamics Profiles, FME Transactions, Vol. 45, No. 3, pp. 412-420.

Lim, H. S., Bae, H. J., Lim, Y. C., Song S. J., Kang, S. H., and Yang, S. S., 2011, Injection Profile Effects on Low Speed Axial Compressor Stability Enhancement, Journal of Mechanical Science and Technology, Vol. 25, No. 6, pp. 1501-1507.

Mazumdar, A., Triantafyllou, M. S., and Asada, H. H., 2015, Dynamic Analysis and Design of Spheroidal Underwater Robots for Precision Multidirectional Maneuvering, IEEE/ASME Transactions on Mechatronics, Vol. 20, No. 6, pp. 2890-2902.

Menter, F. R., 1994, Two-Equation EddyViscosity Turbulence Models for Engineering Applications, AIAA Journal, Vol. 32, No. 8, pp. 2893-2906.

Seo, D., Oh, J., and Jang, J., 2017, Performance Analysis of a Horn-Type Rudder Implementing the Coanda Effect, International Journal of Naval Architecture and Ocean Engineering, Vol. 9, pp. 177184.

Trancossi, M., Madonia, M., Dumas, A.,
Angeli, D., Bingham, C., Das, S. S., Grimaccia, F., Marques, J. P., Porreca, E., Stewart, P., Subhash, M., Sunol, A., and Vecinic, D., A. , 2016b, New Aircraft Architecture based on the ACHEON Coanda Effect Nozzle: Flight Model and Energy Evaluation European Transport Research Review, Vol. 8, No. 11, pp. 1-21.

Trancossi, M., Stewart, J., Subhash, M., and Angeli, D., 2016a, Mathematical Model of a Constructal Coanda Effect Nozzle, Journal of Applied Fluid Mechanics, Vol. 9, No. 6, pp. 28132833.

Versteeg, H. K., and Malalasekera, W., 2007, Introduction to Computational Fluid Dynamics: The Finite Volume Method, Pearson, England.

Wilcox, D. C., 2008, Formulation of the $k-\omega$ Turbulence Model Revisited, DCW Industries Inc., La Cañada, California.

Woud, H. K., and Stapersma, D., 2013, Design of Propulsion and Electric Power Generation System, 2nd Edition, London: IMarEST. 